\title{
Comparative Effects of Overweight on Cardiovascular Risk in Younger Versus Older Men
}

\author{
Brent M. Egan, MD, David R. Bassett, MD, and Walter D. Block, PhD
}

\begin{abstract}
The relation of age and body mass index (BMI) to atherosclerosis risk factors was examined in $\mathbf{3 5 7}$ men. Odder ( $\geq 45$ years) men had higher $(p<0.01$ ) systolic and diastolic blood pressures, fasting cholesterol and glucose, and 1-hour gtucose and insulin levels. Fasting insulin and triglyceride levels were not significantly different between the 2 age groups. Although older men $(n=170)$ had greater values for several risk factors, overweight (BMI $>25.5 \mathrm{~kg} / \mathrm{m}^{2}$ ) increased risk factors more in men younger than 45 years $(n=187$ ). In younger men, those with higher BMls had a greater prevalence, respectively, of blood pressure $>140 / 90 \mathrm{~mm} \mathrm{Hg}$ (35.2 vs 11.2\%, p <0.0001), cholesterol $>200$ $\mathrm{mg} / \mathrm{dl}$ (53.5 vs $29.3 \%$, p <0.001), fasting triglycerides $>150 \mathrm{mg} / \mathrm{dll}$ (38.0 vs 10.3\%, p <0.0001), 1hour glucose $>160 \mathrm{mg} / \mathrm{dl}$ (15.5 vs $5.2 \%, p<0.05$ ), fasting insulin $>11 \mu \mathrm{U} / \mathrm{ml}$ (28.2 vs $5.2 \%$, p $<0.0001$ ), and 1-hour insulin $>110 \mu \mathrm{U} / \mathrm{ml}$ (28.2 vs $9.5 \%, p<0.001$ ). In contrast, among older men, the prevalence of elevated blood pressure, cholesterol, triglycerides and glucose values was not significantly greater in the subgroup with high BMI. However, elevations of fasting (19.6 vs 6.4\%, p $<0.05)$ and 1 -hour insulin (29.3 vs $11.5 \%$, p $<0.01$ ) values were more common among older men with higher BMls. Data indicate that older men have greater vahues for several cardiovascular risk factors than do younger men. Overweight increases the prevalence of cardiovascular risk factors more in younger men.
\end{abstract}

(Am J Cardiol 1991;67:248-252)

From the University of Michigan, Department of Medicine, Division of Hypertension, and the Department of Community Health Programs. Manuscript received July 27, 1990; revised manuscript received and accepted September 20, 1990.

Address for reprints: Brent M. Egan, MD, Medical College of Wisconsin, Division of Cardiology, 8700 W. Wisconsin Avenue, Milwaukee, Wisconsin 53226 .
$\mathrm{O}$ verweight is a risk factor for hypertension, ${ }^{1}$ cardiovascular disease ${ }^{2}$ and premature death. ${ }^{3}$ The risk associated with overweight is not uniformly distributed. For example, overweight increases the risk of cardiovascular disease ${ }^{2}$ and premature death ${ }^{4}$ more in younger men. These observations may be partially explained by data indicating that overweight increases the prevalence of hypertension more in younger men. ${ }^{5}$ However, to our knowledge, differential effects of overweight on the prevalence of other risk factors in these 2 groups are unknown. Age-related differences in the effects of overweight on cardiovascular risk factor profiles in men could have important implications for disease prevention. Consequently, we reviewed our risk factor data in men to assess the relation of age to the cardiovascular risk of overweight.

\section{METHODS}

Patients: Data were obtained on 378 men self-referred to our Atherosclerosis Risk Factor Detection Clinic. Most of the subjects participating in this screening process learned about the clinic through newspaper bulletins or from acquaintances familiar with the program.

Measurements: Height and weight were obtained on lightly clothed subjects without shoes. Body mass index (BMI) was calculated, ${ }^{6}$ and casual (seated) blood pressure was measured by mercury sphygmomanometry. Diastolic blood pressure was determined by phase IV of the Korotkoff sounds. Heart rate was quantified by palpation of the radial pulse. Blood samples were drawn in the fasting state for plasma cholesterol, ${ }^{7}$ triglycerides, ${ }^{7}$ immunoreactive insulin ${ }^{8}$ and whole blood glucose. ${ }^{9}$ Subjects then drank $100 \mathrm{~g}$ of glucose in 10 ounces of water over the next 5 minutes. A 1-hour blood sample was obtained for measurement of whole blood glucose and plasma insulin. In 8 patients studied on or after March 6,1986 , blood glucose was measured in serum ${ }^{10}$ rather than in whole blood. Glucose values from the last 8 persons were converted to whole blood glucose by the formula: whole blood glucose $=($ serum glucose -6$) /$ 1.15. ${ }^{11}$

Top normal values (mean +2 standard deviations [SD]) for fasting and 1-hour insulin were obtained in a subgroup seen in the Atherosclerosis Risk Factor Detection Clinic. These 48 subjects ( 35 men and 13 women) were (1) within $\pm 10 \%$ of ideal body weight, (2) nonsmokers, (3) physically fit according to self-report of moderate to vigorous exercise, (4) normotensive, (5) normolipidemic, and (6) normoglycemic. ${ }^{11}$ No subject 
had a history of hypertension, gout, hyperlipidemia, diabetes, and renal or cardiovascular disease. These subjects had mean fasting insulin values of $4.3 \mu \mathrm{U} / \mathrm{ml}$ (mean $+2 \mathrm{SD}=10.5$ ) and 1-hour insulin of $43.2 \mu \mathrm{U} /$ $\mathrm{ml}($ mean $+2 \mathrm{SD}=110.3)$. Therefore, 11 and 110 were selected as top normal fasting and 1-hour insulin values, respectively. Our values for fasting and 1-hour postglucose $(100 \mathrm{~g})$ insulin levels concur with those obtained by Bjorntorp et $\mathrm{al}^{12}$ in physically fit, non-overweight men who were 54 to 56 years old.

Statistical analysis: Twenty-one men with fasting glucose $>150 \mathrm{mg} / \mathrm{dl}$ or 1 -hour glucose $>250 \mathrm{mg} / \mathrm{dl}$ or a history of diabetes, or any combination of these, were eliminated from the analysis, since the insulinemic response of moderate and severe diabetic patients to an increase in glucose is significantly impaired. ${ }^{13}$ Thus, the final study group consisted of 357 men. Differences between the 2 subgroups of men demarcated by age $<$ vs $\geq 45$ years were assessed by Student's $t$ test. The effect of $\mathrm{BMI}<$ vs $\geq 25.5 \mathrm{~kg} / \mathrm{m}^{2}$ within each subgroup on the prevalence of selected risk factors was examined with chi-square analysis. The triglyceride data were not normally distributed. ${ }^{14}$ The triglyceride values were logarithmically transformed to normalize the distribution. Data analyses were conducted using established statistical programs. ${ }^{15}$

\section{RESULTS}

Descriptive variables (mean \pm standard error of the mean) for the 2 groups of men stratified by age < vs $\geq 45$ years are listed in Table $I$. The age limit was adapted from the Australian Heart Foundation Study which observed a stronger relation between overweight and prevalence of hypertension in men $<45$ years versus other age and gender subgroups. ${ }^{5}$ Older men had greater values than younger men for several risk factors. Table II presents data on men within each age group demarcated by BMI $<25.5$ vs $\geq 25.5 \mathrm{~kg} / \mathrm{m}^{2}$. Overweight tended to cause larger increases of risk factor levels in younger men.

Table III displays the percentage of men in 4 subgroups stratified by age $<$ or $\geq 45$ years and BMI $<$ or $\geq 25.5 \mathrm{~kg} / \mathrm{m}^{2}$ whose values exceeded generally accepted top normal levels for the risk factors measured. The
TABLE I Descriptive Variables for Men Stratified by Age < or $\geq 45$ Years Old

\begin{tabular}{|c|c|c|c|}
\hline $\begin{array}{l}\text { Age } \\
\text { Stratification }\end{array}$ & $\begin{array}{l}<45 \\
(n=187)\end{array}$ & $\begin{array}{l}\geq 45 \\
(n=170)\end{array}$ & $p$ Value \\
\hline Age (years) & $32.4 \pm 0.5$ & $55.6 \pm 0.6$ & $<0.00001$ \\
\hline $\mathrm{BMI}\left(\mathrm{kg} / \mathrm{m}^{2}\right)$ & $25.4 \pm 0.3$ & $26.0 \pm 0.2$ & NS \\
\hline Systolic BP (mm Hg) & $121 \pm 1$ & $130 \perp 1$ & $<0.0001$ \\
\hline Diastolic BP $(\mathrm{mm} \mathrm{Hg})$ & $81 \pm 1$ & $84 \pm 1$ & $<0.04$ \\
\hline HR (beats/min) & $72 \pm 1$ & $73 \pm 1$ & NS \\
\hline $\mathrm{flRl}(\mu \mathrm{U} / \mathrm{ml})$ & $5.9 \pm 0.4$ & $6.1 \pm 0.4$ & NS \\
\hline 1-hour IRI $(\mu \mathrm{U} / \mathrm{ml})$ & $68 \pm 4$ & $85 \pm 4$ & 0.002 \\
\hline $\mathrm{TG}(\mathrm{mg} / \mathrm{dl})$ & $126 \pm 8$ & $135 \pm 7$ & NS $(\log )$ \\
\hline fWBG (rrig/dl) & $91 \pm 1$ & $95 \pm 1$ & $<0.01$ \\
\hline 1-hour WBG (mg/dl) & $115 \pm 2$ & $142 \pm 3$ & $<0.0001$ \\
\hline $\mathrm{TC}(\mathrm{mg} / \mathrm{dl})$ & $190 \pm 3$ & $211 \pm 3$ & $<0.0001$ \\
\hline
\end{tabular}

$B M I=$ body mass index: $B P=$ blood pressure; $f=$ fasting; $H R=$ heart rate; $I R I=$ plasma immunoreactive insulin; $N S=$ not significant $(p>0.05) ; \mathrm{TC}=$ total plasma cholesterol; $T G=$ fasting plasma triglycerides; $W B G=$ whole blood glucose.

BMI cutpoint was also adapted from the Australian Heart Foundation Study which observed a sharp increase in the prevalence of hypertension among men $<45$ years whose BMI exceeded this value. ${ }^{4} \mathrm{~A}$ BMI of $25.5 \mathrm{~kg} / \mathrm{m}^{2}$ corresponds to a Metropolitan Relative Weight of 109 to $113 \%$ according to the 1959 Tables. $^{16}$

The risk factor prevalence data in Table III are based on the following:

1. BLOOD PRESSURE: Systemic hypertension was defined as casual blood pressure $\geq 140 \mathrm{~mm} \mathrm{Hg}$ systolic or $\geq 90 \mathrm{~mm} \mathrm{Hg}$ diastolic, or both (Korotkoff phase IV).

2. ChOlesterol: Cholesterol values $\geq 200 \mathrm{mg} / \mathrm{dl}$ were defined as elevated based on National Cholesterol Education Program guidelines. ${ }^{17}$

3. TRIGLYCERIDES: Triglycerides $>150 \mathrm{mg} / \mathrm{dl}$ were considered abnormal, since decreased high-density cholesterol values are frequent in persons with triglyceride concentrations exceeding that level. ${ }^{18}$

4. FASTING AND ONE-HOUR WHOLE BLOOD GLUCOSE: The upper normal limits for fasting and 1-hour glucose are based on the Fajans-Conn criteria. ${ }^{11}$

5. FASTING AND ONE-HOUR INSULIN: Normal limits for fasting and 1-hour insulin values are defined in Methods.

Younger ( $<45$ years) overweight men (BMI $\geq 25.5$ $\mathrm{kg} / \mathrm{m}^{2}$ ) had a significantly higher prevalence for mea-

TABLE II Effect of Overweight on Selected Risk Factors in Younger and Older Men

\begin{tabular}{|c|c|c|c|c|c|c|}
\hline & \multicolumn{3}{|l|}{ Men <45 Years } & \multicolumn{3}{|l|}{ Men $\geq 45$ Years } \\
\hline & $\begin{array}{l}<25.5 \mathrm{~kg} / \mathrm{m}^{2} \\
(\mathrm{n}=116)\end{array}$ & $\begin{array}{l}\geq 25.5 \mathrm{~kg} / \mathrm{m}^{2} \\
(\mathrm{n}=71)\end{array}$ & $p$ Value & $\begin{array}{l}<25.5 \mathrm{~kg} / \mathrm{m}^{2} \\
(n=78)\end{array}$ & $\begin{array}{l}\geq 25.5 \mathrm{~kg} / \mathrm{m}^{2} \\
(\mathrm{n}=92)\end{array}$ & p Value \\
\hline $\mathrm{BMI}\left(\mathrm{kg} / \mathrm{m}^{2}\right)$ & $23.0 \pm 0.2$ & $29.3 \pm 0.4$ & $\leq 0.0001$ & $23.4 \pm 0.2$ & $28.2 \pm 0.2$ & $\leq 0.0001$ \\
\hline Systolic BP & $119 \pm 1$ & $126 \pm 2$ & $\leq 0.002$ & $130 \pm 2$ & $130 \pm 2$ & NS \\
\hline Diastolic BP & $78 \pm 1$ & $86 \pm 1$ & $\leq 0.0001$ & $83 \pm 1$ & $84 \pm 1$ & NS \\
\hline HR (beats/min) & $71 \pm 1$ & $73 \pm 1$ & NS & $72 \pm 1$ & $73 \pm 1$ & NS \\
\hline $\mathrm{fIRI}(\mu \mathrm{U} / \mathrm{ml})$ & $4.2 \pm 0.3$ & $8.6 \pm 0.8$ & $\leq 0.0001$ & $4.7 \pm 0.4$ & $7.4 \pm 0.6$ & $\leq 0.0002$ \\
\hline 1-hour IRI $(\mu \cup / \mathrm{ml})$ & $53 \pm 3$ & $93 \pm 7$ & $\leq 0.0001$ & $69 \pm 5$ & $98 \pm 6$ & $\leq 0.0003$ \\
\hline fWBG (mg/dl) & $88 \pm 1$ & $96 \pm 2$ & $\leq 0.0001$ & $94 \pm 1$ & $95 \pm 13$ & NS \\
\hline 1-hour WBG (mg/dl) & $106 \pm 3$ & $129 \pm 4$ & $\leq 0.0001$ & $142 \pm 4$ & $143 \pm 4$ & NS \\
\hline $\mathrm{TG}(\mathrm{mg} / \mathrm{dl})$ & $97 \pm 4$ & $172 \pm 17$ & $\leq 0.0001$ & $137 \pm 13$ & $134 \pm 7$ & NS \\
\hline $\mathrm{TC}(\mathrm{mg} / \mathrm{dl})$ & $184 \pm 3$ & $200 \pm 4$ & $\leq 0.001$ & $209 \pm 4$ & $213 \pm 4$ & NS \\
\hline
\end{tabular}




\begin{tabular}{|c|c|c|c|c|}
\hline \multirow[b]{2}{*}{$\begin{array}{l}\mathrm{BMI}\left(\mathrm{kg} / \mathrm{m}^{2}\right) \\
\text { Risk Factor }\end{array}$} & \multicolumn{2}{|l|}{$<45$ Years } & \multicolumn{2}{|c|}{$\geq 45$ Years } \\
\hline & $\begin{array}{l}<25.5 \\
(n=116)\end{array}$ & $\begin{array}{l}\geq 25.5 \\
(n=71)\end{array}$ & $\begin{array}{l}<25.5 \\
(n=78)\end{array}$ & $\begin{array}{l}\geq 25.5 \\
(n=92)\end{array}$ \\
\hline Htn & 11 & $35^{* * * * *}$ & 44 & 41 \\
\hline TC & $\begin{array}{c}1.77 \\
29 \\
0.07\end{array}$ & $\begin{array}{c}1.4 \\
54^{* * * *} \\
14\end{array}$ & $\begin{array}{l}13 \\
55 \\
26\end{array}$ & $\begin{array}{l}11 \\
65 \\
5.4\end{array}$ \\
\hline TG & 10 & $38^{* * * *}$ & 28 & 30 \\
\hline fWBG & 1.7 & 5.6 & 2.6 & 3.3 \\
\hline 1-hour WBG & 5.2 & $15.5^{*}$ & 18 & 24 \\
\hline$f|R|$ & 5.2 & $28^{* * * * *}$ & 6.4 & $20^{*}$ \\
\hline 1-hour IRI & 9.5 & $28 * * *$ & 11.5 & $29^{* *}$ \\
\hline
\end{tabular}

sured risk factor variables, except fasting glucose, than leaner men of similar age (Table III). Older men manifested smaller BMI-related increases in the prevalence of risk factors. Figure 1, which is based on data in Table III, shows the excess and relative risks of overweight for selected risk factors separately for younger and older men.

\section{DISCUSSION}

Differences in risk factor values between younger and older men: Men $\geq 45$ years old had higher values than younger men for several risk factors including systolic and diastolic blood pressure, fasting cholesterol and glucose, and 1-hour glucose and insulin. 19,20 However, other risk factors including $\mathrm{BMI},{ }^{21}$ heart rate $^{22}$ and fasting triglyceride ${ }^{23}$ insulin levels ${ }^{24}$ were not significantly different between the 2 groups (Table I).

Influence of overweight on risk factor values within each age group: Overweight younger men had significantly greater values for measured risk factor variables except heart rate (Table II). The effect of overweight was generally less among older men (Tables II and III and Figure 1). Overweight younger men have a cardiovascular risk factor profile (Table III) comparable to older men who are at the greatest absolute risk of cardiovascular disease. ${ }^{2}$

Blood pressure: Overweight (BMI $>25.5 \mathrm{~kg} / \mathrm{m}^{2}$ ) was associated with a threefold higher prevalence of hypertension in younger men. In contrast, overweight was

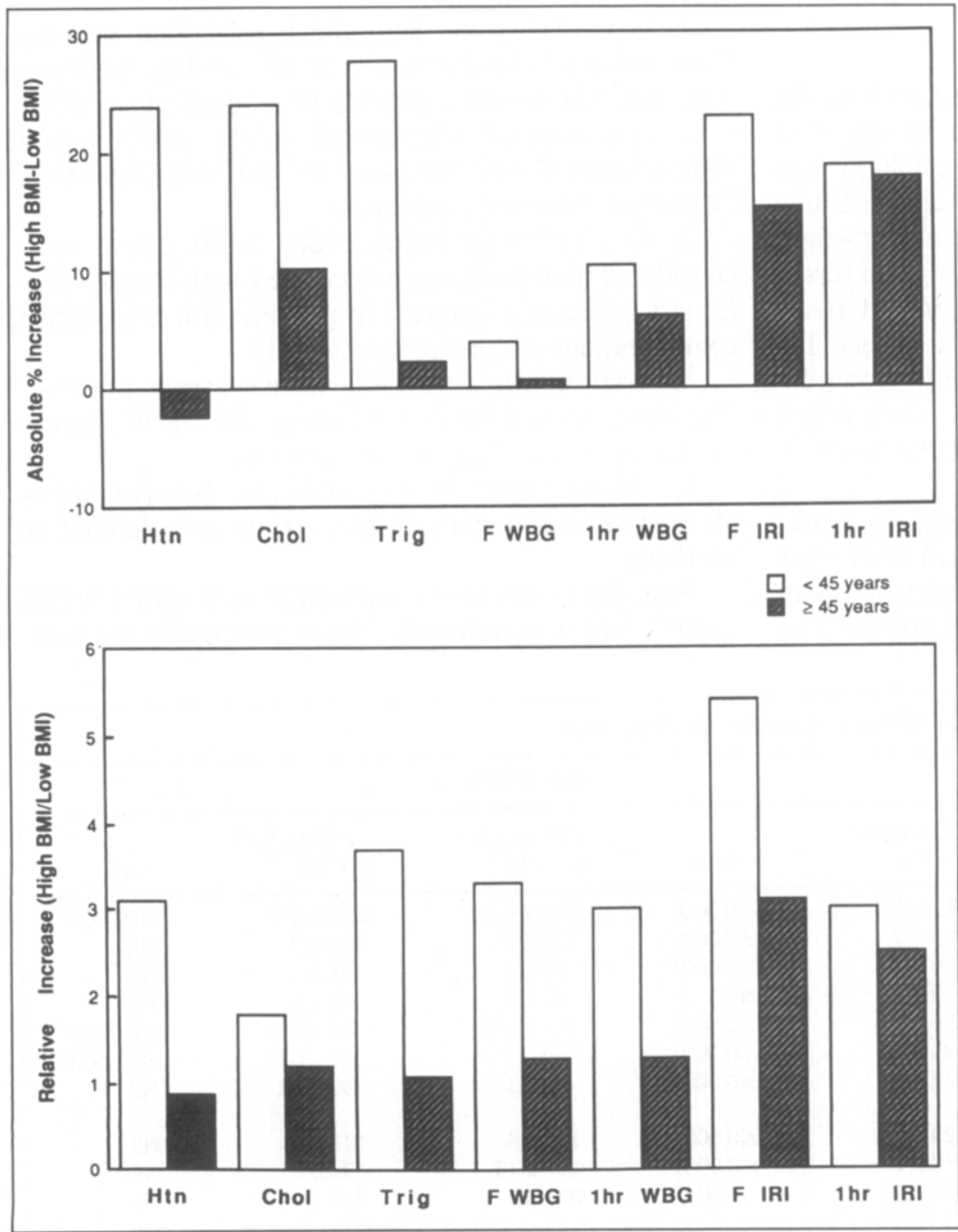

FIGURE 1. Effect of body mass index (BMI) on the excess (top panel) and relative (bottom panel) risk for selected cardiovascular risk factors in men stratified by age. Chol = cholesterol; $F$ = fasting; Htn = hypertension; IRI = plasma immunoreactive insulin; TRIG = trigtycerides; $W B G=$ whole blood glucose. 
not associated with a significantly greater prevalence of hypertension in our sample of men $>45$ years. These data are similar to the findings of the Australian Heart Foundation study ${ }^{5}$ which reported a stronger relation of weight to hypertension in men $<45$ years old compared with other age and gender subgroups. Nevertheless, overweight may increase the risk of heart failure in both younger and older hypertensive subjects by imposing a dual burden of elevated preload on a heart working against a higher afterload. ${ }^{25}$

Insulin: An association between weight, insulin and hypertension was reported. ${ }^{26}$ Insulin levels, per se, are an unlikely explanation for the stronger association between overweight and hypertension in younger men, since overweight increased the prevalence of fasting and 1-hour hyperinsulinemia in both age groups (Table III, Figure 1). However, insulin induces greater neurogenic activation in men $<40$ vs men $>60$ years old. ${ }^{27}$ These findings could contribute to the greater plasma norepinephrine and vascular $\alpha$-adrenergic tone in overweight versus leaner young men. ${ }^{28}$ Consequently, differences of insulin action rather than insulin concentration may explain greater effects of overweight on blood pressure in younger versus older men.

Glucose: Older men had higher values for fasting and 1-hour glucose despite higher 1-hour insulin values (Table I). This suggests that insulin resistance contributes to an age-related decline of glucose tolerance in our subjects. The prevalence of fasting hyperglycemia was sufficiently low in all subgroups to the extent that no significant differences were observed. However, the agecorrected prevalence of 1-hour hyperglycemia ${ }^{1}$ was significantly increased by overweight only in younger men. However, as noted previously, overweight was associated with an increase in 1-hour hyperinsulinemia in both younger and older men (Table III, Figure 1). These data suggest that overweight is associated with greater resistance to insulin's effects on glucose disposal or suppressing gluconeogenesis, or both, in younger men.

Triglycerides: Younger men had a larger BMI-related increase in the prevalence and relative risk of hypertriglyceridemia (Table III, Figure 1). However, insulin normally suppresses hepatic very low density lipoprotein production. ${ }^{29}$ Thus, a greater weight-related hepatic resistance to insulin in younger men may explain our triglyceride data.

Cholesterol: Cholesterol levels were higher in older men (Table I). Overweight significantly increased the prevalence of cholesterol values $>200 \mathrm{mg} / \mathrm{dl}$ only in younger men. The absence of a significant effect of overweight on cholesterol values in men 50 to 79 years old was documented previously. ${ }^{30}$ Although the cause for these age-related differences is unknown, greater effects of overweight on $\alpha$-adrcnergic tone in younger men could partially explain these observations. ${ }^{31}$

Limitations of this cross-sectional study and comparisons to previous epidemiologic investigations: These data were obtained on self-referred men who may not reflect health characteristics of the general male population. Since we observed age-related differences in the association between weight and several cardiovascular risk factors, comparison of BMI values in our subjects with larger samples of U.S. men is of particular interest. The mean $\pm \mathrm{SD} B M I$ values for men aged 30 to 39 and 50 to 62 years in the National Health and Nutrition Survey II were $25.6 \pm 4.0$ and $26.2 \pm 3.9 \mathrm{~kg}$ / $\mathrm{m}^{2}$, respectively. ${ }^{32}$ These BMI values are very similar to those for the younger and older men in this study $(25.4$ \pm 4.0 and $26.0 \pm 2.6 \mathrm{~kg} / \mathrm{m}^{2}$, respectively).

The results from our study are consistent in other respects with observations from larger surveys. First, in the Australian Study, ${ }^{5}$ the strongest relation between weight and blood pressure was observed in men aged $<45$ years. Second, the relatively minimal differences in cholesterol between overweight and leaner elderly men were also noted previously. ${ }^{30}$ Third, whereas older men have higher values than younger men for several risk factors, our data (Table II) are consistent with reports that overweight has greater adverse health effects in younger men. ${ }^{2,4,5}$ In fact, increased cardiovascular risk for younger men begins at mild levels of overweight. ${ }^{2,5}$ Because the mean BMI for men of this age group ( $\mathrm{Ta}$ ble I) lies at the margin of increased risk, large numbers of younger men are affected. ${ }^{32}$

This study did not address potential explanations for the greater risk of overweight in younger versus older men. The lower apparent risk of overweight in older men may reflect premature mortality in younger men with high-risk obesity. ${ }^{4,32}$ Another possibility is that older men with BMIs $<25.5 \mathrm{~kg} / \mathrm{m}^{2}$ may have sufficient adiposity (replacing lean mass) to raise their risk factors.

Our data extend previous observations by showing that overweight is associated with a significant increase in prevalence not only of elevated blood pressure but also of cholesterol, triglycerides and 1-hour glucose in younger men. The relative risk of overweight for each of these variables appears to be less in older men. Overweight is associated with significant elevations of fasting and 1-hour hyperinsulinemia in both age groups. However, our interpretation of the data suggests that overweight influences insulin action more adversely in younger men.

Acknowledgment: We are grateful for the expert assistance of Maria Borondy in examining many of the subjects seen in the Atherosclerosis Risk Factor Detection Clinic; Mary Frescura in preparing the manuscript; Janet Kniffen, Luciana $\mathrm{Yu}$ and Mark McGinnis in performing laboratory assays; and Jill Kneisley and Nicholás Schork for the data analyses. Portions of this work were presented at the Forty-fifth Annual Meeting of the Midwest Section, AFCR, Chicago, Illinois (Clin Res 35:847A: 1987).

\section{REFERENCES}

1. Kannel WB, Brand N, Skinner JJ, Dawber TR, McNamara PM. The retation of adiposity to blood pressure and development of hypertension. Ann Intern Med 1967;67:48-59.

2. Hubert HB, Feinleib M, McNamara PM, Castelli WP. Obesity as an independent risk factor for cardiovascular disease: a 26-year follow-up of participants in the Framingham Heart Study. Circulation 1983;67:968-977. 
3. Garrison RJ, Feinleib M, Castelli WP, McNamara PM. Cigarette smoking as a confounder of the relationship between relative weight and long-term mortality. The Framingham Heart Study. JAMA 1983;249:2199-2203.

4. McCue H Jr. The 1979 build and blood pressure study. In: Bostrom H, Ljungstedt N, eds. Medical Aspects of Mortality Statistics. Stockholm: Almquist \& Wiksell International, 1981:182-198.

5. MacMahon SW, Blacket RB, Macdonald GJ, Hall W. Obesity, alcohol consumption and blood pressure in Australian men and women. The National Hear1 Foundation of Australia Risk Factor Prevalence Study. J Hypertens 1984;2:8591.

6. Keys A, Fidanza F, Karvonen MJ, Kimura N, Taylor HL. Indices of relative weight and obesity. J Chron Dis 1972;25:329-343.

7. Lipid Research Clinics Program. Manual of Laboratory Operations. vol 1.

Lipid and Lipoprotein Analysis. (DHEW publication no. (NIH) 75-628)

8. Morgan CR, Lazarow A. Immunoassay of insulin: two antibody system:

plasma insulin levels of normal, subdiabetic and diabetic rats. Diabetes 1963;

12:115-126.

9. Hoffman WS. A rapid photoelectric method for the determination of glucose in blood and urine. $J$ Biol Chem 1937,120:51-55.

10. Horvath $C$, Pedersen $H$. Immobolized enzymes in continuous flow analysis. In: Advances in Automated Analysis: Technicon International Congress, 1976. Mediad Inc., 1977:86-95.

11. Report of the Committee on Statistics of the American Diabetes Association: standardization of the oral glucose tolerance test. Diabetes 1969;18:299-310.

12. Bjorntorp P, Fahlen M, Grimby G, Gustafson A, Holm A, Renstrom P, Schersten T. Carbohydrate and lipid metabolism in middle-aged physically welltrained men. Metabolism 1972;21:1037-1043

13. Fraze E, Donner CC, Swislocki ALM, Chiou YA, Chen YD, Reaven GM. Ambient plasma free fatty acid concentrations in noninsulin-dependent diabetes mellitus: evidence for insulin resistance. $J$ Clin Endocrinol Metab 1985;61:807811.

14. Shapiro SS, Wilk MB. An analysis of variance test for normality. Biometrika 1965;52:591 61 I

15. Fox DJ, Guire KE. Documentation for MIDAS. 3rd ed. Statistical Research Laboratory, University of Michigan, 1976.

16. Statistical Bulletin. Metropolitan Life Insurance Company 1959:40:1-4

17. Report of the National Cholesterol Education Program expert panel on detection, evaluation, and treatment of high blood cholesterol in adults. Arch Intern Med 1988;148:36-69.

18. Miller GJ, Miller NE. Plasma high density lipoprotein concentration and development of ischaemic heart disease. Lancet 1975;1:16-19.
19. Welborn TA, Wearne K. Coronary heart disease incidence and cardiovascular mortality in Busselton with reference to glucose and insulin concentrations. Diabetes Care 1979;2:154-160.

20. Pyorälä K, Savolainen E, Kaukola S, Haapakuski J. Plasma insulin as coronary heart disease risk factor: relationship to other risk factors and predictive value during $91 / 2$-year follow-up of the Helsinki Policemen Study population. Acta Med Scand 1985;70I(suppl):38-52.

21. Bray GA. Obesity and the heart. Mod Concepts Cardiovase Dis $1987 ; 56: 67$ 71.

22. Dyer AR, Persky V, Stamler J, Paul O, Shekelle RC, Berkson DM, Lepper $M$, Schoenberger JA, Lindberg HA. Heart rate as a prognostic factor for coronary heart disease and mortality: findings in three Chicago epidemiologic studies. Am $J$ Epidemiol 1980;1 12:736-749.

23. Hamsten A, Walldius G, Dahlen G, Johansson B, De-Faire U. Serum lipoproteins and apolipoproteins in young male survivors of myocardial infarction. Atherosclerosis 1986;59:223-235.

24. Ducimetiere P, Eschwege E, Papuz L, Richard JL, Claude JR, Rosselin G Relationship of plasma insulin levels to the incidence of myocardial infarction and coronary heart disease mortality in a middle-aged population. Diabetologia 1980;19:205-210.

25. Messerli FH. Obesity in hypertension: how innocent a bystander? Am J Med 1984;77:1077-1082

26. Modan M. Halkin H, Almog S, Lusky A, Eshkol A. Shefi M. Shitrit A, Fuchs Z. Hyperinsulinemia. A link between hypertension, obesity and glucose tolerance. $J$ Clin Invest 1985;75:809-817.

27. Minaker KL, Rowe JW, Young JB, Sparrow D, Pallotta JA, Landsberg L. Effect of age on insulin stimulation of sympathetic nervous system activity in man. Metabolism 1982;31:1181-1184

28. Egan BM, Schork NJ, Weder AB. Regional hemodynamic abnormalities in overweight men. Am $J$ Hypertens 1989;2:428-434

29. Tobey TA, Greenfield M, Kraemer F, Reaven GM. Reiationship between insulin resistance, insulin secretion, very low density lipoprotein kinetics and plasma triglyceride levels in normotriglyceridemic man. Mctabolism 1981;30: $165-171$

30. Barrett-Connor E, Khaw KT. Is hypertension more benign when associated with obesity? Circulation 1985:72:53-60.

31. Dzau VJ. Mechanism of the interaction of hypertension and hypercholesterolemia in atherogenesis: the effects of antihypertensive agents. Am Heart $J$ 1988;116:1725-1728

32. Simopoulos AP, Van Itallie TB. Body weight, health, and longevity, Ann Intern Med 1984;100:285-295. 